\title{
Tecnologias Assistivas e Digitais na Educação Especial: o que foi possível realizar em
}

\section{tempos de pandemia da Covid-19}

\author{
Assistive and Digital Technologies in Special Education: what was possible to achieve in Covid-19 \\ pandemic times \\ Tecnologías Digitales y de Asistencia en Educación Especial: lo que se podía lograr en tiempos de \\ pandemia Covid-19
}

Thayane Nascimento Freitas ORCID: https://orcid.org/0000-0002-0456-5039 Secretaria Municipal de Educação de Teresina, Brasil

E-mail: thayanny_freitas@hotmail.com

Rosane Ferreira Macêdo

ORCID: https://orcid.org/0000-0001-9871-7031 Secretaria de Educação e cultura do Maranhão, Brasil E-mail: rosafilinto2016@gmail.com

Rogério Leal de Sousa

ORCID: https://orcid.org/0000-0001-5597-2761 Secretaria Municipal de Picos, Brasil E-mail: rogeriolealsousa@gmail.com

Fausneto Alves Ibiapina

ORCID: https://orcid.org/0000-0002-8991-5375 Secretaria de Educação do Piauí, Brasil

E-mail: fausneto.i@hotmail.com

Ivone das Dores de Jesus

ORCID: https://orcid.org/0000-0003-0843-907X Universidade Estadual do Maranhão, Brasil E-mail: ivonedasdores@hotmail.com

Lilían de Sousa Sena

ORCID: https://orcid.org/0000-0002-1137-8194 Secretaria de Educação e Cultura do Maranhão, Brasil

E-mail: liliandisousa@hotmail.com

Ilka Márcia Ribeiro de Souza Serra

ORCID: https://orcid.org/0000-0003-1622-5434

Universidade Estadual do Maranhão, Brasil E-mail: ilka.tt@gmail.com

\begin{abstract}
Resumo
O referido artigo apresenta uma abordagem a respeito das tecnologias assistivas e digitais na educação especial: o que foi possível realizar em tempos de pandemia da Covid-19. Tem como objetivo identificar quais as tecnologias assistivas e digitais foram utilizadas pelos docentes no ensino remoto aos estudantes público-alvo da educação especial em duas escolas da rede pública municipal de Teresina e, uma em Picos-PI, durante a pandemia da Covid-19. Para o desenvolvimento da pesquisa, se fez inicialmente uma pesquisa de campo de cunho exploratório, a partir de uma abordagem qualitativa. Para coleta de dados utilizamos entrevistas semiestruturadas, optamos nesta pesquisa, pelo tipo descritiva, como complemento, utilizou-se o método indutivo com o propósito de melhor expor o objeto de estudo aqui apresentado. Como possíveis resultados observamos que a utilização das tecnologias assistivas e digitais ainda não ocorrem de forma efetiva nas práticas pedagógicas durante o ensino remoto aos estudantes com deficiência, deixando-os em uma inclusão mascarada, ou seja, excluídos. Assim, acredita-se que a formação continuada dos docentes sobre as tecnologias digitais e assistivas faz-se necessária para favorecer inclusão nas práticas pedagógicas no ensino remoto, bem como a interlocução ente os professores da sala regular e do atendimento educacional especializado, com intuito de viabilizar um trabalho colaborativo que favoreça a participação efetiva desses estudantes público-alvo da educação especial.
\end{abstract}

Palavras-chave: Tecnologias digitais; Tecnologias assistivas; Educação especial; Ensino remoto; Covid-19. 


\begin{abstract}
The referred article presents an approach regarding assistive and digital technologies in special education: what was possible in times of Covid-19 pandemic. It aims to identify which assistive and digital technologies were used by teachers in remote education for students targeting special education in two public schools in Teresina and one in Picos-PI, during the Covid-19 pandemic. For the development of the research, an exploratory field research was initially carried out, based on a qualitative approach. For data collection we used semi-structured interviews, we opted in this research, for the descriptive type, as a complement, we used the inductive method in order to better expose the object of study presented here. As possible results, we observed that the use of assistive and digital technologies does not yet occur effectively in pedagogical practices during remote teaching to students with disabilities, leaving them in a masked inclusion, that is, excluded. Thus, it is believed that the continuing education of teachers on digital and assistive technologies is necessary to favor inclusion in pedagogical practices in remote education, as well as the dialogue between teachers in the regular classroom and specialized educational services, in order to enable collaborative work that favors the effective participation of these students target audience of special education.
\end{abstract}

Keywords: Digital technologies; Assistive Technologies; Special education; Remote teaching; Covid-19.

\title{
Resumen
}

El artículo referido presenta un enfoque sobre las tecnologías de asistencia y digitales en la educación especial: lo que era posible en tiempos de la pandemia de Covid-19. Su objetivo es identificar qué tecnologías de asistencia y digitales fueron utilizadas por los maestros en educación remota para estudiantes dirigidos a educación especial en dos escuelas públicas en Teresina y una en Picos-PI, durante la pandemia de Covid-19. Para el desarrollo de la investigación se realizó inicialmente una investigación exploratoria de campo, basada en un enfoque cualitativo. Para la recolección de datos utilizamos entrevistas semiestructuradas, optamos en esta investigación, para el tipo descriptivo, como complemento, usamos el método inductivo con el fin de exponer mejor el objeto de estudio aquí presentado. Como posibles resultados, observamos que el uso de tecnologías asistenciales y digitales aún no se da de manera efectiva en las prácticas pedagógicas durante la enseñanza a distancia a estudiantes con discapacidad, dejándolos en una inclusión enmascarada, es decir, excluidos. Así, se cree que la formación continua de los docentes en tecnologías digitales y asistenciales es necesaria para favorecer la inclusión en las prácticas pedagógicas en la educación a distancia, así como el diálogo entre los docentes en el aula regular y los servicios educativos especializados, a fin de posibilitar el trabajo colaborativo. que favorezca la participación efectiva de estos alumnos público objetivo de educación especial.

Palabras clave: Tecnologías digitales; Tecnologías de asistencia; Educación especial; Enseñanza remota; Covid-19.

\section{Introdução}

Ao discorrermos sobre educação especial na perspectiva da inclusão, é necessário fazermos uma reflexão sobre inclusão versus estigma, pois a inclusão vem se tornando uma temática bastante usual no contexto da modernidade. As transformações sociais, tecnológicas, econômicas e políticas acontecem com grande velocidade, acentuando ainda mais o perfil excludente da sociedade. A inclusão está ligada ao combate da exclusão social de diversas categorias como: classe social, nível educacional, deficiência, idosos, entre outras, que por vez ou outra, não tem acesso às oportunidades oferecidas pela sociedade. Contudo, a inclusão que aqui trataremos é a inserção das pessoas com deficiência no meio escolar. No entanto, a acessibilidade a essas pessoas é ainda limitada, muitas barreiras são encontradas em todos os lugares.

Sendo assim, as “pessoas com deficiência”, denominação utilizada nos dias de hoje e presente na lei n 13.146/2015 (conhecida como Lei Brasileira de Inclusão da Pessoa com Deficiência), ainda são compreendidas durante toda a história da sociedade sob diversas nuances de exclusão, seguindo a cultura de cada época, com isso a forma de tratar os deficientes e sua escolarização foi pautada nesta ideologia de construção cultural.

No século XX, ocorreram grandes avanços nas metodologias de ensino para este público supracitado, em relação aos direitos humanos, com efeitos do reconhecimento como cidadãos, devendo conviver e estudar em uma perspectiva inclusiva. Sendo assim, destacamos alguns documentos legais, importantes, que asseguraram com veemência esses direitos, como: a Declaração Universal dos Direitos Humanos (1948) a Constituição Federal (1988), a Declaração de Jomtien (1990), a Declaração de Salamanca (1994), a Lei de Diretrizes e bases da Educação Nacional - LDBEN 9.394/1996, a de Guatemala (1999), a Política da Educação Especial na Perspectiva da Inclusão (2008) e a Lei Brasileira de Inclusão (2015).

No campo das tecnologias assistidas e digitais, especificamente na área educacional, oportunizam instrumentos formativos como facilitadores no contexto do ensino-aprendizagem, a fim de que se possa qualificar o acesso ao conhecimento 
na vida dessas pessoas com deficiência. De acordo com Radabaugh (1993), para as pessoas com deficiência a tecnologia torna as coisas possíveis, e a tecnologia que é utilizada para esse público é conhecida como Tecnologia Assistiva - TA, que é um termo utilizado para "identificar todo o arsenal de recursos pedagógicos, tecnológicos e de suporte, os quais contribuem para proporcionar ou ampliar habilidades funcionais de estudantes público-alvo da educação especial, na perspectiva de promover autonomia e a inclusão." (Bersch \& Tonolli, 2006, p.89)

$\mathrm{Na}$ realização desta pesquisa, vivenciamos um momento de Pandemia mundial, causada por um vírus denominado SARS-CoV-2, que causa a COVID-1919 , e que desencadeou um esvaziamento nas escolas, e com isso, o cancelamento das aulas presenciais. Com esta mudança, tivemos que inovar nossas aulas com a utilização de ferramentas digitais para proporcionar a continuidade do ano letivo iniciado. Pois segundo as autoridades responsáveis pela manutenção de serviços essenciais, como o Ministério da Educação-MEC, através da Portaria n 544 de 16 de junho de 2020, que substituiu as aulas presenciais por aulas em meio digitais, utilizando as tecnologias digitais em rede, por meio das aulas remotas.

Fundamentado nesse contexto justifica-se o interesse em investigar como as pessoas com deficiência estão participando das aulas remotas com o uso das tecnologias assistivas e digitais. A problemática levantada no presente trabalho consiste em conhecer quais as tecnologias assistivas e digitais utilizadas para o ensino remoto aos estudantes público-alvo da educação especial em duas escolas da rede pública municipal de Teresina e, outra em Picos-PI, durante a pandemia da COVID19.

Neste sentido, o objetivo do artigo foi identificar quais as tecnologias assistivas e digitais foram utilizadas pelos docentes no ensino remoto aos estudantes público-alvo da educação especial em duas escolas da rede pública municipal de Teresina e, uma em Picos-PI, durante a pandemia da Covid-19, e especificadamente, conhecer as tecnologias assistivas e digitais utilizadas como estratégias por estas escolas da rede pública municipal de ensino no período de pandemia da Covid19; Descrever as experiências positivas e/ou negativas dos docentes na execução das aulas no ensino remoto utilizando as tecnologias assistivas e digitais; e por fim, analisar os impactos das aulas remotas com uso das tecnologias para o ensinoaprendizagem dos estudantes público-alvo da educação especial nas escolas de Teresina-PI e Picos-PI.

\section{Educação e Pandemia: diretrizes e realidades}

O Brasil e o mundo enfrentam uma emergência em saúde pública em virtude da pandemia da Covid 19. Considerando alguns documentos como a declaração da Organização Mundial da Saúde (OMS), que de emergência em saúde pública, classificação de pandemia, a infecção humana pelo novo Corona vírus (COVID-19), em 11 de março de 2020, anterior a essa declaração, a Portaria n 188/GM/MS, de 04 de fevereiro de 2020, declara Emergência em Saúde Pública de Importância Nacional, em razão da infecção humana causada pelo COVID-19, a LEI Federal No 13.979/2020, de 06 de fevereiro de 2020, que dispõe sobre as medidas de enfrentamento da emergência em saúde pública decorrente do vírus SARS-COV2, dentre elas o isolamento e a quarentena e também uma Medida Provisória n ${ }^{\circ} 934$, de $1^{\circ}$ de abril de 2020, que estabelece o seu artigo " $1^{\circ} \mathrm{O}$ estabelecimento de ensino de educação básica fica dispensado, em caráter excepcional, da obrigatoriedade de observância ao mínimo de dias de efetivo trabalho escolar". Fez-se necessário o isolamento social, o que impediu as pessoas a saírem de casa para realizarem suas atividades rotineiras. Sendo assim, umas das áreas mais afetadas foi a educacional, que precisou fechar as escolas e manter os estudantes, servidores e professores em suas residências.

Durante o período de Pandemia, o Conselho Nacional de Educação fez-se necessário aprovar no dia 28 de abril de 2020, as diretrizes para orientar as escolas da educação básica e as instituições de ensino superior, com intuito de nortear os estados e municípios para o atendimento ao direito do aprendizado em todo território nacional, prevendo todos os direitos e

${ }^{1}$ A COVID-19 é uma doença causada pelo coronavírus, denominado SARS-CoV-2, que apresenta um espectro clínico variando de infecções assintomáticas a quadros graves. (Brasil, 2020) 
objetivos de aprendizagem para cada etapa educacional, de acordo com a Base Nacional Comum Curricular. Assim, ressalta-se que o Parecer do Conselho Nacional de Educação/CP No 05/2020, foi aprovado em 28 de abril de 2020, com destaque ao:

[...]desenvolvimento do efetivo trabalho escolar por meio de atividades não presenciais é umas das alternativas para reduzir a reposição de carga horária presencial ao final da situação de emergência e permitir que os estudantes mantenham uma rotina básica de atividades escolares mesmo afastado do ambiente físico da escola. (Brasil, 2020, p. 7)

Ressalta-se que as atividades propostas durante o período de pandemia devem levar em consideração as condições tecnológicas, estruturais, emocionais, a ausência física do professor, as necessidades especiais do estudante e as condições precárias de muitas famílias, para que de fato possa ocorrer a interação professor- estudante e, consequentemente, o ensinoaprendizagem. Tornou-se primordial pensar em possibilidades de momentos de contato, manutenção de vínculos, ainda que virtualmente, para que os estudantes continuassem a aprender usando outros recursos, como as tecnologias digitais em rede.

Assim o Conselho Estadual de Educação do Piauí através da resolução nº 87/2020 estabeleceu normas para as escolas pertencentes às redes que integram o Sistema de Educação do Estado, e, sendo como base para as redes municipais do estado, em que nesse período de excepcionalidade desde a reorganização do calendário nas etapas da educação básica, das modalidades de ensino e nas avaliações de aprendizagem. Na resolução CEE/PI nº 87/2020, consta que:

Art. 5 VIII - Utilização de recursos oferecidos pelas Tecnologias de Informação e Comunicação para os estudantes do Ensino Fundamental, Médio e da Educação Profissional de nível técnico, considerando como modalidade não presencial quaisquer atividades didáticas, módulos ou unidades de ensino, cujo foco maior é a autoaprendizagem e com a mediação de recursos didáticos organizados em diferentes suportes de informação que utilizem tecnologia da informação e comunicação de modo remoto (Piauí, 2020).

O município de Picos-Piauí, localizado a 307 km da capital Teresina, aprovou o Parecer CME/PI no 004/2020 que dispõe sobre o regime especial de aulas não presenciais para as instituições integrantes do Sistema Municipal de Ensino, de acordo com as orientações feitas pelo Conselho Municipal de Educação e Sistema Municipal de Picos-PI. A Secretaria Municipal de Picos adotou o programa "Educação \& Família Construindo Saberes, que está de acordo com o Artigo 32, § 4 da LDB "estabelece que o ensino fundamental será presencial, sendo o ensino a distância utilizado como complementação da aprendizagem ou em situações emergenciais". Assim foi implantado na rede municipal durante o ano letivo de 2020. Segundo a resolução CNE/PI n 004/2020, art.5:

Parágrafo Único: O Programa Educação \& Família Construindo Saberes se caracteriza pela manutenção de vínculos e por disseminar conhecimentos na perspectiva de leitura e letramento, bem como resolução de problemas, de modo online e off-line, em moldes que mesclam momentos em que aluno estuda sozinho, e/ou com professores, mediados por tecnologia ou não. (Piaú́, 2020)

Sendo assim, enfatiza-se que as equipes escolares utilizaram estratégias e ferramentas gratuitas disponíveis, e mais adequadas aos estudantes matriculados na rede. A comunicação de forma online entre professores, estudantes e famílias ocorreram por meio de plataforma de mensagens, tais como: Google Sala de Aula - sala de aula virtual onde foi possível promover debates, aplicar questionários, agendar atividades, interações pedagógicas; YouTube - canal de postagem de videoaulas, documentários e transmissões; Podcast - conteúdo em áudio de forma descontraída; Mural de atividades; Quizzes questões desafiadoras ; Aulas da TV Escola (gravadas); Whats App - opcional para interação direta com a família.

Teresina, a capital do Piauí, além das bases nacional e estadual, elaborou as diretrizes gerais para o retorno das aulas presenciais na Rede Pública Municipal de Teresina, com base no decreto municipal n 19.886, de 03.07.2020 que despôs sobre normas, regras de funcionamento econômico; decreto municipal $\mathrm{n}^{\circ} 19.787$ de 28.05.2020, que autorizou a SEMEC 
regulamentar sobre atividades presenciais; decreto municipal 19.810 de 04.06 .2020 que dispõe sobre atividades pedagógicas não presenciais e a extensão do trabalho durante a suspensão das aulas presenciais; portaria da SEMEC. n $^{\circ}$ 259/2020 de 02.06.2020 que aprova as diretrizes do regime especial das atividades pedagógicas não presenciais.

A Rede Municipal de Teresina continuou com as atividades pedagógicas não presenciais, cabendo a cada Unidade de Ensino elaborar um plano de atendimento individual aos estudantes com dificuldade de aprendizagem. Para o atendimento não presencial a referida secretaria disponibilizou as unidades de ensino:

a) A Plataforma Mobieduca.Me, ambiente web para acompanhamento das atividades remotas. Essa ferramenta pedagógica possibilita a hospedagem de videoaulas, envio de atividades, acompanhamento individual dos alunos, registros de aulas e controle da frequência dos alunos.

b) Plataforma Em casa eu Aprendo, como um canal de comunicação oficial da Secretaria Municipal de Educação de Teresina, visando a prestação de serviço para o corpo técnico-docente com o objetivo de disponibilizar informações conteúdos didático-pedagógico, durante as aulas presenciais. $\mathrm{O}$ acesso à plataforma é feito pelo endereço eletrônico (www.escola.semec.pmt.pi.gov.br) ou por meio de link vinculado ao site da própria secretaria (www.semec.teresina.pi.gov.br/).

c) Além das possibilidades citadas acima, cada Unidade de Ensino poderá utilizar outras ferramentas como aplicativos de mensagens, redes sociais, Google Suíte, material impresso, videoconferências e outros, conforme as especificidades. (TERESINA, 2020)

A realidade a qual vivemos é desconhecida para todos e devemos trabalhar em conjunto para o enfrentamento e adaptações necessárias para essa nova realidade, enfatizando uma oportunidade para fortalecer a relação educação e família, e vale ressaltar, que as determinações do Conselho Nacional de Educação, junto ao Ministério da Educação, assumem as diretrizes pertinentes à educação no país lançando luz sobre como amenizar os problemas pertinentes ao período de pandemia.

\section{Reflexões Sobre o uso das Tecnologias Digitais e Assistivas}

O contexto educacional vivenciado atualmente, intermediado por recursos tecnológicos e digitais, nos faz refletir enquanto sujeitos atuantes e/ou não atuantes no uso destas tecnologias, sobre o poder socio-interacional que esta tem provocado diante da pandemia causada pela COVID-19.

Diversos tipos de tecnologias foram sendo relocadas para outros fins, e não apenas para entretenimentos, por exemplo, o uso de aplicativos como Whats App e YouTube, que são plataformas de comunicação e interação, e eram mais utilizados para entreter, e hoje são vistos também como ferramentas de transmissão de conteúdos escolares e interação.

A educação, tem propiciado a quebra dos "muros" da escola, tanto levando o mundo exterior para dentro da sala de aula, como conectando estudantes e professores fora do tempo e espaços escolares. $\mathrm{O}$ uso das plataformas de interação com o intuito de dar continuidade ao ano letivo, como as mídias sociais, fazem parte de nosso cotidiano, só que ainda carece por parte dos profissionais e estudantes, habilidades para o uso produtivo dessas mídias em sala de aula, em prol da construção de saberes dos estudantes.

Compreender o que é a tecnologia, é necessário para direcionarmos o uso para fins educacionais, visto que a "tecnologia engloba a totalidade de coisas que a engenhosidade do cérebro humano conseguiu criar em todas as épocas, suas formas de uso, suas aplicações, ela é variável e contextual” (Kenski, 2012, p.23). Para o clima emergencial, esperamos que seja eficaz o uso das tecnologias digitais que estão sendo utilizados neste período pandêmico, ainda é necessário um aprofundamento destes conceitos para que possamos alcançar a todos os estudantes, sejam estes público-alvo da educação especial- PAEE ou não.

Perdura ainda a ideia de que ser uma escola tecnológica ou com inclusão digital, é ter uma sala de informática com computadores de última geração e, com um professor para atuar exclusivamente naquela sala, obviamente esta é importante 
porque é um recurso que ajuda a minimizar a exclusão de muitos que não tem acesso, porém "o computador não vai, por si só, modificar a concepção de aprendizagem das escolas, uma vez que ele pode ser usado para lidar com diversas situações" conforme Coscarelli (2017 p.27), devemos utilizá-lo como meio de comunicação, fonte de informação e ajudar nossos estudantes a serem mais independentes na busca de conhecimento, levantando questionamentos e desenvolvendo projetos educacionais, saindo das aulas tradicionais.

A escola não pode ficar inerte diante dessa realidade social, visto que, esta é o espaço de compartilhamento de saberes também, nesse ambiente deve e pode se utilizar das TDICs para subsidiar as transformações e acompanhar o avanço da sociedade da informação afim de preparar os estudantes para a atuação no contexto social de maneira mais crítica e participativa. (Souza, 2019)

Como espaço social e agência formadora, a escola deve oferecer educação a todos, conforme legislações dispostas na LDB nº 9394/96, incluindo assim pessoas com deficiência, transtornos globais do desenvolvimento, altas habilidades e/ou superdotação, que fazem parte do público-alvo da educação especial (PAEE). Para esse público que necessita de um ensino especializado, voltado para inclusão que respeite suas especificidades provenientes das deficiências e/ou dificuldades, também devem fazer uso das tecnologias, visto que esta é utilizada para facilitar nossas vidas. e para esses estudantes PAEE, tornarem a aprendizagem possível, e que potencializem suas forças e demonstrem suas habilidades de forma cada vez mais independente.

Trabalhar na perspectiva da educação inclusiva com esses estudantes salienta mudanças importante, pois, se outrora, eram atendidos exclusivamente por escolas especiais, agora pela abordagem da inclusão, a meta é que esses estudantes frequentem as escolas regulares, tendo o apoio da equipe do Atendimento Educacional Especializado-AEE em Sala de Recursos Multifuncionais.

Visando o atendimento às necessidades educativas dos estudantes com deficiência, utilizar recursos de Tecnologia Assistiva (TA) tem promovido um bom desenvolvimento e emancipação dos mesmos, tornando possível o acesso dos estudantes PAEE às mais diversas atividades escolares. A TA é considerada como:

uma área do conhecimento, de característica interdisciplinar, que engloba produtos, recursos, metodologias, estratégias, práticas e serviços que objetivam promover a funcionalidade, relacionada à atividade e participação, de pessoas com deficiência, incapacidades ou mobilidade reduzida, visando sua autonomia, independência, qualidade de vida e inclusão social (Brasil, 2007).

O conceito de TA não deve estar restrito apenas a recursos para a sala de aula, mas para todos os ambientes da escola, pois visa proporcionar ao estudante com deficiência, a sua autonomia, valorizando suas potencialidades, a qualidade de vida e uma maior inclusão com estímulos e motivação para que este participe ativamente do seu processo de construção de conhecimentos. Pensando assim, é notório perceber que toda a equipe escolar tem responsabilidade de criar ambientes acessíveis e inclusivos, e não apenas o professor. (Bersch, 2008)

O comitê de Ajudas técnicas-CAT diz que "a aplicação de Tecnologias Assistivas abrange todas as ordens do desempenho humano, desde as tarefas básicas de autocuidado até o desempenho de atividades profissionais" (CAT 2007, p.11), corroborando com o autor supracitado, em que diz que as TA são organizadas e classificadas de acordo com os objetivos a quem se destina, que podem ser para auxílios para a vida diária e vida prática.

$\mathrm{O}$ uso das tecnologias digitais e assistivas, requer que o docente tenha uma formação que contemple esses conhecimentos, pois, todo esse processo tecnológico, acabou por fazer emergir um universo virtual que ao mesmo tempo é paralelo ao universo físico e que é possível através de uma interconexão mundial de computadores em rede, que chamamos de ciberespaço. Pois, segundo Mallagi (2019, p.20), é “[...] um sistema de comunicação eletrônica global que reúne os humanos e computadores em uma relação simbiótica, que cresce exponencialmente graças à comunicação interativa.” 
Espera-se que o perfil do professor possa atender as necessidades da sociedade atual, imersa na tecnologia e, que no período pandêmico, se utiliza de uma tecnologia digital em rede, ocupando um ciberespaço, contemple uma formação que se aproxima mais da figura de um provocador do que de um mero transmissor de conhecimentos, levando em consideração as necessidades de todos os seus aprendentes, incluindo o PAEE. Tudo isso, porque se desejamos formar sujeitos críticos e dotados de competências como a criatividade, a flexibilidade, a capacidade de resolver problemas, tornam-se atributos indispensáveis para atuação na sociedade atual e inclusiva que almejamos.

Para a consolidação da educação especial na perspectiva inclusiva, é imprescindível uma boa formação de docentes, pois este é o profissional que atua diretamente com os estudantes, considerando que com uma boa prática pedagógica, ele promoverá ou não o acesso à aprendizagem dos discentes (Papim et al. 2018). É necessário oferecer formação teórica e prática relacionadas às tecnologias digitais e assistivas aos docentes para que estes tenham possibilidades de ofertar um trabalho mais inclusivo por meio de recursos pedagógicos e didáticos, conforme as especificidades de cada estudante, principalmente os que fazem parte do PAEE.

\section{Metodologia}

A pesquisa em questão é de natureza qualitativa, do tipo descritiva, como complemento, utilizou-se o método indutivo com o propósito de melhor expor o objeto de estudo aqui apresentado. Para Oliveira (2008, p. 37) a abordagem qualitativa remete ao "processo de reflexão e análise da realidade através da utilização de métodos e técnicas para compreensão detalhada do objeto de estudo em seu contexto histórico e/ou segundo sua estruturação".

A utilização da abordagem qualitativa ocorreu no sentido de compreender as questões investigadas, a partir da perspectiva dos participantes, explorando suas percepções, atitudes e motivações na tentativa de entender o processo de aprendizagem, e toda sua complexidade na utilização de tecnologias assistivas e digitais na educação especial, no ensino remoto, na Pandemia da Covid-19.

\subsection{Instrumentos, participantes e campo de Pesquisa}

Essa pesquisa foi realizada em três escolas de Ensino Fundamental, sendo duas escolas localizadas em Teresina-PI e uma escola na cidade de Picos-PI. As escolas são todas de ensino fundamental de $1^{\circ}$ a $5^{\circ}$ ano e da rede municipal de ensino.

Os instrumentos utilizados na coleta de dados se deram através de questões que compõem a entrevista semiestruturada, com um total de cinco (05) questões abertas e fechadas, que foram feitas direcionadas ao tema aqui apresentado, objetivando a construção e o desenvolvimento de novos e importantes conhecimentos acerca do tema. A utilização das entrevistas não estruturadas de acordo com Gil (2007, p.94) é onde o entrevistado tem liberdade para desenvolver cada situação em qualquer direção que considere adequada, como uma forma de explorar mais amplamente a questão, tendo em geral perguntas abertas podendo ser respondidas dentro de uma conversação informal.

Os procedimentos realizados na pesquisa ocorreram por meio da aplicação de entrevista à distância, ou seja, diante do isolamento social, e com a impossibilidade de reunir-se, foi feito primeiramente o comunicado e a solicitação, em seguida foi feito o repasse dos termos aos entrevistados, que após concordarem em participarem da pesquisa, receberam a entrevista via WhatsApp ou e-mail, foi dado a devolutiva utilizando a mesma via de recebimento.

Quanto aos participantes da pesquisa, foram três, sendo dois professores que atuam em Teresina -PI, e uma professora que atua no município de Picos-PI. Os professores lecionam no corrido ano com estudantes com deficiência que estão sendo atendidos via ensino remoto. 


\section{Resultados e Discussão}

\subsection{Perfil dos participantes da pesquisa}

O caminho percorrido para a produção dos dados desta pesquisa partiu da busca por meio de entrevista e análise dos conhecimentos dos professores acerca das tecnologias assistivas e digitais. Dessa forma, utilizamos o instrumento da entrevista, por meio desse recurso foi possível obter informações relevantes sobre a perspectiva dos sujeitos participantes acerca da temática. Os dados gerados, foram organizados seguindo a ordem das perguntas semiestruturadas, e serão apresentados no Quadro 1, a seguir.

Quadro 1 - Perfil dos participantes da pesquisa, "As tecnologias assistivas e digitais utilizadas pelos docentes no ensino remoto aos estudantes da educação especial"

\begin{tabular}{|c|c|c|c|c|}
\hline $\begin{array}{c}\text { NOMES FICTÍCIOS } \\
\text { PROFESSORES } \\
\text { PARTICIPANTES } \\
\text { DA PESQUISA }\end{array}$ & $\begin{array}{l}\text { TEMPO DE } \\
\text { DOCÊNCIA }\end{array}$ & $\begin{array}{c}\text { FORMAÇÃO } \\
\text { ACADÊMICA } \\
\text { INICIAL }\end{array}$ & $\begin{array}{c}\text { FORMAÇÃO } \\
\text { CONTINUADA EM } \\
\text { TECNOLOGIA } \\
\text { (DIGITAL E/OU } \\
\text { ASSISTIVA) }\end{array}$ & $\begin{array}{c}\text { LECIONAM PARA } \\
\text { ESTUDANTES COM } \\
\text { DEFICIÊNCIA NO } \\
\text { CORRENTE ANO? }\end{array}$ \\
\hline Professor 1 (P1) & 7 anos & Pedagogia & Não & Sim \\
\hline Professor 2 (P2) & 17 anos & $\begin{array}{l}\text { Pedagogia e Ed. } \\
\text { Física. }\end{array}$ & Não & Sim \\
\hline Professor 3 $(\mathbf{P 3})$ & 2 anos & Normal Superior & & \\
\hline
\end{tabular}

Fonte: Elaborado pelos autores (2021).

O quadro acima evidencia o perfil dos professores que participaram da pesquisa, para manter o anonimato, denominamos os docentes com nomes fictícios, utilizando P1, P2 e P3. As análises dos dados foram coletadas através de uma entrevista semiestruturada aplicada a três (03) professores, onde foi possível organizar as informações acerca do tema que será detalhado ao longo do texto. (Quadro 1)

No Quadro 1, é notório as diferenças de tempo de experiência docente e formação inicial, dentre os entrevistados percebemos que a P2 por ter 17 anos de docência, já sentiu a necessidade de fazer muitas formações continuadas, por exemplo, na área de tecnologias digitais e assistivas, na pós-graduação lato sensu de AEE, e as demais professoras não falaram se tinham formação em outras áreas.

Os cursos de formação inicial de professores, infelizmente ainda não abrangem, em suas estruturas curriculares, conhecimentos tão peculiares e específicos que abordem a TA de forma satisfatória que prepare os professores para atuar usando a TA como recurso inclusivo. As práticas pedagógicas destes professores no decorrer do processo de escolarização, podem impulsionar o aprendizado dos estudantes PAEE e ajudar a implementar um ambiente escolar cada vez mais inclusivo, mas lembrando que este não é papel apenas do professor, mas de toda a comunidade escolar. (Manzini, 2011)

Para entendermos como os professores utilizam as tecnologias, precisamos saber a sua concepção sobre os termos que posterior seriam aprofundados nas perguntas, então, ao serem questionados sobre "o que compreendem sobre tecnologia assistiva e tecnologia digital", se posicionaram assim:

P1- É o uso da tecnologia para promover a aprendizagem dos alunos de maneira autônoma.

P2- As tecnologias assistivas são áreas do conhecimento que englobam várias estratégias, objetivando promover a participação de pessoas com deficiência e limitações cognitivas ou motoras.

As tecnologias digitais na educação visam promover um leque de possibilidades para acessar informações precisas e atualizadas, contribuindo assim para o desenvolvimento imediato e constante de professores, alunos e responsáveis, facilitando na resolução de problemas que possam surgir.

P3-Eu entendo que a tecnologia assistiva vem para suprir necessidades básicas desde uma rampa de acesso a um aparelho auditivo, vai da necessidade de cada aluno com deficiência, e as tecnologia digitais são instrumentos que podem enriquecer a atividade pedagógica. 
$\mathrm{Na}$ fala dos sujeitos, demonstram não serem leigos quando aos termos TA e TD, visto que, P1 e P3 veem a tecnologia como instrumento que promove a autonomia na aprendizagem dos estudantes e auxilia na inclusão escolar, enquanto P2 demonstra uma visão mais aprofundada e funcional das tecnologias digitais e assistivas, onde é notório perceber a perspectiva de inclusão da mesma, que é voltada para uma educação emancipatória e para todos, sejam eles PAEE ou não.

No contexto educacional para utilizar-se das TA, os professores devem conhecer os conceitos de tecnologias digitais e assistivas, e compreender que são utilizadas para os estudantes com deficiência ou com necessidades educacionais especiais, visando romper barreiras sensoriais, motoras ou cognitivas que venham impedir o pleno acesso ao conhecimento por estes, e que nessas tecnologias há um fortalecimento da participação ativa e autônoma dos estudantes, possibilitam a participação efetiva na construção do conhecimento. (BERSCH, 2017)

Durante o período das atividades remotas, as estratégias de implementação das atividades deverão estar voltadas na identificação e eliminação das barreiras no desenvolvimento do ensino-aprendizagem. Para proporcionar o acesso aos estudantes público-alvo da educação especial no ensino remoto foi destacado pelos professores que:

P1. Basicamente nenhuma estratégia foi ou está sendo utilizada para viabilizar a aprendizagem dos alunos, visto que este tipo de ensino possui muitas barreiras para os alunos sem necessidade de atendimento especial, para aqueles que necessitam este problema aumenta de forma exponencial.

P2.A secretaria de Educação não desenvolveu nem um plano de ação que pudesse favorecer o desenvolvimento e o aprendizado dos alunos com deficiência durante esse período de pandemia.

P3 As aulas passam na tv em canal aberto, temos uma plataforma onde são colocadas as atividades do dia e vídeos educativos a todos os alunos e os alunos especiais recebem atividades direcionadas a eles por nossa coordenadora do AEE. E ainda ficamos à disposição das mães ou responsáveis via WhatsApp.

Não houve estratégias por meios digitais por parte das instituições do ensino regular pertencentes ao P1 e P2 para com os estudantes público-alvo da educação especial que proporcionassem a inclusão destes no processo ensino-aprendizagem. Segundo Straub (2020, p. 46)

Compreendemos que a educação mediada pelas tecnologias exerce um papel de extrema importância na constituição de um cidadão ativo, pensante e conectado, pois promove uma nova forma de conceber o aprendizado, de fazer, de pensar e de conceber a própria sociedade.

Já a instituição referente ao P3, houve as estratégias através das mídias digitais, para que os estudantes, público-alvo da educação especial tivesse acesso, mas além disso "os professores precisam ser formados para uma nova didática, nova pedagogia, considerando as mudanças que ocorreram, devido à internet, na forma de ensinar e com o próprio conhecimento" (STRAUB, 2020, p.40, apud Mayrink, 2017).

Com a introdução do ensino remoto surgem diversas metodologias para o acesso e desenvolvimento do fazer pedagógico, na qual o professor inicia um processo de informação e desenvolvimentos de competências digitais, sendo que o mesmo deve iniciar um processo de formação continuada dentro do arcabouço tecnológico, porém de acordo com as observações descritas pelos professores nesse período ocorreu uma ausência nessa formação tecnológica, onde eles destacam que:

P1-A formação continuada oferecida pela secretaria de educação municipal tem sugerido algumas atividades e usos de aplicativos nas aulas, porém a falta de acesso à internet de qualidade elou celulares e computadores melhores pelos alunos inviabiliza muitas opções sugeridas.

$\boldsymbol{P 2}$ - Infelizmente não ocorreu formações.

P3-No período da pandemia não ouve nenhum treinamento voltado as aulas remotas. 
A formação do professor para a utilização das TDIC e tecnologias assistivas no ensino remoto foi insuficiente e em determinadas situações não foi direcionada, segundo Masetto (2006, p.146) a apropriação pelo professor dessas tecnologias promoverá uma mediação coerente, onde poderá ser um facilitador da aprendizagem e não apenas um transmissor de conteúdo vinculado aos meios tecnológicos.

Para uma atuação efetiva pelo professor sobre as TIC é necessário de acordo com Coutinho (2011), conhecimento a nível científico ou dos conteúdos, a nível pedagógico e a nível tecnológico, o qual foi denominado por Mishra e Kolher (2006) como Technological Pedagogical Content Knowledge ou TPACK. Propondo uma combinação entre os níveis, para que com base nos conhecimentos pedagógicos e dos conteúdos, se apropriasse do conhecimento tecnológico com intuito de melhorar o nível de aprendizagem e coparticipação do estudante no seu processo de aprendizagem.

De acordo com Koehler e Mishra (2008) apud Coutinho (2011, p.7), direciona a formação de professores para o desenvolvimento do TPACK numa forma gradual e em espiral, começando a formação com tecnologias mais simples e que os professores já conhecem, rumo a aplicação cada vez mais complexas e sofisticadas. Assim, com base nos conhecimentos tecnológicos e pedagógicos pode favorecer uma medição pedagógica mais coerente e de acordo com sua realidade no ensino remoto.

O ensino remoto nas escolas evidenciadas utilizou algumas ações diferenciadas de acordo com a realidade de cada uma. Observamos que todas tiveram dificuldades para o acesso do estudante com alguma deficiência, com relação ao seu acesso e permanência nesses novos espaços de aprendizagem, devido a fatores que vão desde os recursos técnicos, computador, celular, rede de internet compatível, bem como a participação efetiva do professor de sala e de um professor especializado para o acompanhamento desse estudante com deficiência. Os professores relatam que as principais dificuldades encontradas na utilização das tecnologias assistivas e digitais com estudante que tenha alguma necessidade educacional especial, foram:

P1-Falta de acesso à internet, celular ou computador e a presença de um mediador capacitado no ensino. P2-São inúmeras as dificuldades, uma vez que precisamos estar preparados para lidar com as tecnologias assistivas e digitais, e isso só é possível através do oferecimento de cursos de formação dos docentes, capacitando-os para atuar com alunos especiais, facilitando assim no acompanhamento dos alunos.

P3- $O$ acesso e a falha de treinamento dos profissionais da educação. eu mesma sentir muitas dificuldades para trabalhar com as aulas remotas, devido minha falta da prática e manuseio com aparelhos eletrônicos.

Dentre as dificuldades elencadas pelos professores fica evidente que a formação para utilização das tecnologias assistivas e digitais possui papel fundamental no desenvolvimento das aulas remotas. Com essa ausência de formação, o acesso ao estudante com deficiência se torna mais complexo, pois não permite uma mediação pedagógica efetiva. Esse distanciamento evidenciou que não ocorre um trabalho colaborativo entre o professor de sala e o professor especializado, oportunizando um distanciamento desse estudante de uma real inclusão.

A importância de um fazer pedagógico em conjunto preconiza uma realidade escolar diferenciada, na qual o professor possui um papel muito importante de mediador, que de acordo com Oliveira (2015) apud Vílchez (2018, p.20):

O professor (seja especialista ou não na área da deficiência) deve cumprir um papel mediador e de empatia, que procure a participação ativa dos estudantes com deficiência nesse percurso de inclusão. Para conseguir fazê-lo, o professor deve passar por constantes processos de capacitação ou especializações nesses quesitos para que possa conhecer e aprofundar maneiras de interagir e ensinar aos estudantes com deficiência, por meio de metodologias tradicionais ou inovadoras, e com o uso das tecnologias que possam ser adaptadas, segundo as necessidades deles (Oliveira, 2015; Fiorini; Manzini, 2015). 
A formação do professor deve ser priorizada pela escola, para que ele possa realizar um trabalho com coerência e diversificado. Não basta apenas realizar diversos cursos, mas é fundamental estar em constante trabalho colaborativo com os demais. As trocas de experiências com os colegas podem transformar sua prática. No ensino remoto essa prática não deve ser diferente, esse trabalho deve existir propondo situações em que o estudante com deficiência participe ativamente, não apenas deixando a cargo do professor especializado, mas propor alternativas que esse estudante também possa ser coparticipante do seu conhecimento.

\section{Considerações Finais}

As práticas educacionais direcionadas ao uso das tecnologias assistivas e digitais, sejam elas em educação inclusiva ou em geral, ainda enfrentam dificuldades para sua execução. Diante do contexto de pandemia foi evidenciado que essa utilização teve de ser popularizada e o surgimento das barreiras ficou explícito durante a pesquisa, devido à ausência de formações aos professores, sem o acesso a diversas metodologias e o uso das tecnologias na educação, dificultando o acesso às informações e desenvolvimento dos estudantes com deficiência.

Terminada a fase de análise e interpretação dos dados da pesquisa, cabe tecer algumas considerações sobre o que acreditamos constituir o cerne do estudo realizado. Sendo assim, foi possível fazermos algumas observações pertinentes, como a compreensão das dificuldades tecnológicas dos professores e o acesso a essa tecnologia por parte do estudante, dificultando seu conhecimento, pois em determinada realidade antes da pandemia, as atividades eram direcionadas apenas ao professor de AEE, de forma presencial e não ocorrendo um ensino colaborativo, onde os envolvidos fizessem uma comunicação sobre esse estudante, deixando claro que a inclusão era apenas para integrar o estudante nas atividades e não a sua efetiva inclusão. Destacamos que mesmo no ensino remoto não deve ser deixado de lado esse trabalho colaborativo, pois quando o professor especializado compartilha atividades e estratégias para trabalhar com o estudante com deficiência, está dando condições para que este possa ter as mesmas oportunidades de aprendizagens.

Nessa nova realidade imposta pelo isolamento social é de extrema importância que o professor tenha acesso e formação sobre as tecnologias digitais e assistivas para que possa compreender melhor as estratégias que possa vir a desenvolver com os estudantes, onde deve haver um fazer pedagógico em conjunto, para que essas orientações possam ser somadas e utilizadas para favorecer a aprendizagem. Assim, é imprescindível que ocorra ações por parte dos gestores em conjunto com os professores especializados e professores de sala regular que proporcionem contato, formações sobre o como realizar essas adaptações, interferências para incluir o estudante com deficiência e que ele venha a participar ativamente nesse processo de ensino remoto.

Percebemos a necessidade de uma formação continuada que possa atender as necessidades dos estudantes com deficiência, fortalecendo assim uma melhor condição de inclusão escolar, que permita o pleno desenvolvimento educacional, seja em ensino remoto ou presencial. Pois, a pandemia trouxe para pauta o que parecia estar encoberto, a desigualdade social. Puxando o olhar de políticas públicas, com a finalidade de resoluções, para o enfático conhecimento promulgado na lei de Diretrizes e Bases da Educação: a educação como direito de todo cidadão.

Dessa forma, podemos concluir que, precisamos fomentar um aprendizado baseado na perspectiva inclusiva em todos os âmbitos, e em tempos de pandemia, que seja uma inclusão digital com tecnologias assistivas. É perceptível que existe uma tentativa de inclusão por parte dos professores, mas que encontram grandes dificuldades em detrimento do ambiente excludente social, por conseguinte, da escola que precisa avançar, para que os estudantes PAEE também alcancem os objetivos proposto na educação para todos, e se a possibilidade escolar emergente é de uma educação remota, então que estes sejam incluídos digitalmente por meio de currículos adaptados e tecnologias assistivas. 
Face às discussões e reflexões sobre as práticas pedagógicas e o uso de tecnologias assistivas e digitais, numa perspectiva inclusiva, presentes neste artigo, percebe-se que há questões que incidem sobre a aprendizagem dos estudantes PAEE. Questões estas que vão desde aspectos socioeconômicos à formação docente. Dessa forma, torna-se evidente a necessidade de pesquisas futuras que tratem do uso de tecnologias assistivas e digitais com intencionalidade pedagógica, além da importância do trabalho colaborativo, para que profissionais da educação e demais pesquisadores possam aprofundar o conhecimento sobre educação inclusiva e tecnologias, de modo a garantir efetivamente o direito à educação inclusiva de qualidade.

\section{Referências}

Brasil. (1996). Lei $n^{o}$ 9.394, de 20 de dezembro de 1996. Estabelece as diretrizes e bases da educação nacional. http://www.planalto.gov.br/ccivil_03/leis/19394.htm

Brasil. (2004) A Educação Especial na Perspectiva da Inclusão Escolar. Recursos pedagógicos acessíveis e comunicação aumentativa e alternativa. Ministério da Educação. Secretaria de Educação Especial. Brasília.

Brasil. (2015) Lei no 13.146/2015, de 06 de julho de 2015. Diário Oficial da União, Poder Legislativo, Brasília, DF, 7 jul. 2015. p. 2. Institui a Lei Brasileira de Inclusão da Pessoa com Deficiência (Estatuto da Pessoa com Deficiência.

Brasil. (2015) Parecer CNE/CP No: 5/2020. Conselho Nacional de Educação. Distrito Federal. Recuperado http://portal.mec.gov.br/index.phpoption=com _docman\&view=download\&alias=145011-pcp005-20\&category_slug=marco-2020-pdf\&Itemid=30192.

Bersch, R. (2006) Tecnologia assistiva e educação inclusiva. Ensaios Pedagógicos, Brasília: Seesp/Mec, p. 89-94.

Bersch, R. (2008) Introdução À Tecnologia Assistiva. CEDI-Centro Especializado em Desenvolvimento Infantil.

Cat. (2007) Comitê de Ajudas Técnicas Secretaria Especial dos Direitos Humanos da Presidência da República (CORDE/SEDH/PR). Ata da Reunião VII.

Corona Vírus-Covid-19 (2021). Sobre a doença. Ministério da Saúde. https://coronavirus.saude.gov.br/sobre-a-doenca.

Coscarelli, C. V.; \& Ribeiro, A. E. (orgs). (2017). Letramento Digital: aspectos sociais e possibilidades pedagógicas. 3 ed. Belo Horizonte: Ceale, Autêntica,

Coutinho, C. P. (2011) TPACK: em busca de um referencial teórico para a formação de professores em tecnologia educativa. Revista Científica de Educação a Distância.2(4).

Gil, A. C. (2007) Como elaborar projetos de pesquisa. (4a ed.), Atlas.

Kenski, V. M. (2012). Educação e tecnologia: O novo ritmo da informação. (8a ed.), Papirus.

Mallagi, V. A C. (2019). Comunicação, tecnologias interativas e educação: (re)pensar o ensinar-aprender na cultura digital. Appris.

Manzini, E. J. (2011) Formação de Professores e Tecnologia Assistiva. In Caiado, K.R.M.; Jesus, D.M.; Baptista, C. R. (Orgs.). Professores e educação especial: formação em foco. Porto Alegre: Mediação, pp.-45-63

Masetto. M. T. (2006) Mediação pedagógica e o uso da tecnologia. In: Moran, J. M. Masetto, M. T; Behrens, M. A. Novas tecnologias e mediação pedagógica. (8a ed.): Papirus, pp.133-173.

Mishra, P.; \& Koehler, M. J. (2006). Tecnológica conteúdo pedagógico conhecimento: a quadro para conhecimento do professor. Registro da faculdade de professores, 108, 1017-1054.

Oliveira, M. M. de. (2008) Como fazer pesquisa qualitativa. (3a ed.), Vozes, 2008.

Radabaugh, M. P. (1993) Chapter 5: Technology For Access And Function. - Technology for Access and Function Research Section Two: NIDDR Research Agenda. NIDRR's Long Range Plan. http://www.ncddr.org/rpp/techaf/lrp_ov.html

Souza, F. M. de; \& Santos, G. de F. (2019) Velhas práticas em novos suportes? As tecnologias digitais como mediadoras do complexo processo ensinoaprendizagem de línguas. São Paulo:Mentes Abertas. (2a ed.),

Straub, S. L. W. (2020) Laboratórios de Informática das Escolas Públicas Estaduais Mato-Grossenses: uma análise discursiva da realidade educacional. Cáceres: UNEMAT Editora, 35-47.

Papim, A. A. P.; Araújo, M. A.; Paixão, K. M. G.; \& Silva, G. F. (Org.) (2018) Inclusão escolar: perspectivas e práticas pedagógicas contemporâneas. Fi, 4969.

Piauí. (2020) RESOLUÇÃO CEE/PI $n^{o}$ 087/2020. Conselho Estadual de Educação http://www.ceepi.pro.br/Arquivos\%20do\%20mural/NOTA\%20T\%C3\%89CNIA\%20001.2020-19.05.2020.pdf

Estadual. Teresina, 26 mar. 2020

Picos. (2020). Resolução CME- $N^{o} 003 / 2020$ de 14 de setembro de 2020. Conselho Municipal de Educação. 
Research, Society and Development, v. 11, n. 3, e4111326211, 2022

(CC BY 4.0) | ISSN 2525-3409 | DOI: http://dx.doi.org/10.33448/rsd-v11i3.26211

Teresina. (2020) Portaria 259/2020/GAB/SEMEC. Diretrizes Gerais para o Regim e Especial de Atividades Pedagógicas não Presenciais. http://www.semec.teresina.pi.gov.br/cat_view/131-normativas-regulatorias-para-educacao-municipal-no-contexto-da-covid-19

Vilchez, I. C. C. (2018). Uma escola em Transformação: reflexões essenciais de uma educação inclusiva para estudantes com deficiência. In Papim, Â. A. P.; Araújo, M. A. de; Paixão, K. de M. G.; Silva, G. de F. da (Orgs.) Inclusão Escolar: perspectivas e práticas pedagógicas contemporâneas- Editora Fi. 